\title{
STRATEGI PENATAAN PKL DI JALAN DEWI SARTIKA KOTA BOGOR
}

\section{Structuring Strategies for Street Vendors on Dewi Sartika street of Bogor City}

\author{
Rudy Mashudi 1, Manuntun Parulian Hutagaol 2, Sri Hartoyo ${ }^{2}$ \\ ${ }^{1}$ Kepala Seksi Aplikasi Telematika dan Pengelolaan Data Elektronik, \\ Kantor Komunikasi dan Informatika Kota Bogor. Email : mashudi.rudy@gmail.com \\ ${ }^{2}$ Staff Pengajar Departemen Ilmu Ekonomi. Fakultas Ekonomi dan Manajemen - Institut Pertanian Bogor \\ E-mail: parulian_gaol@yahoo.com, shty@indo.net.id
}

\begin{abstract}
Street vendor problem in Bogor City has been a part of development agenda priorities since 10 years ago. But its arrangement has not been implemented optimally. For instance, there are some areas which are not arranged yet, as on Jl. Dewi Sartika. The characteristic of street vendors who choose strategic place which is passed by many people and close to central activities, needs a special arrangement strategic. Therefore, Bogor city becomes a comfortable city as people hope. Based on SWOT and AHP analysis, other prioritized strategies are: street vendor policy review (0.350), improving Government and street vendor partnership (0.267), facilitating business space and business safety (0.218) and optimizing city infrastructure and facility (0.165).
\end{abstract}

Key Word: Street vendor, Bogor City, Strategi, arrangement

\section{ABSTRAK}

Pedagang Kaki Lima (PKL) di Kota Bogor telah menjadi bagian dari prioritas agenda pembangunan sejak 10 tahun yang lalu. Namun pengaturannya belum dilaksanakan secara optimal. Misalnya, ada beberapa daerah yang tidak diatur lagi, seperti di Jl. Dewi Sartika. Karakteristik PKL yang memilih tempat strategis dimana dilalui oleh banyak orang dan dekat dengan pusat kegiatan, membutuhkan strategis pengaturan yang khusus. Oleh karena itu, Kota Bogor diharapkan dapat menjadi kota yang nyaman bagi masyarakat dan pengunjung kota Bogor. Berdasarkan analisis SWOT dan AHP, strategi prioritas adalah: tinjauan kebijakan PKL (0,350), meningkatkan kemitraan Pemerintah dan penjual jalanan $(0,267)$, memfasilitasi ruang usaha dan keselamatan bisnis $(0.218)$ dan mengoptimalkan infrastruktur kota dan fasilitas $(0,165)$.

Kata Kunci: PKL, Kota Bogor, Strategi, Peraturan

\section{PENDAHULUAN}

Dinamika pertumbuhan dan perkembangan ekonomi dunia tidak hanya dipengaruhi oleh sektor formal, namun juga dipengaruhi oleh sektor informal. Sektor informal turut berkontribusi dalam kegiatan ekonomi, terutama di negaranegara berkembang di dunia (Loayza, 1997 : 1). Indonesia sebagai salah satu negara berkembang menjadi salah satu negara yang juga mengalami perkembangan sektor informal, terutama setelah masa krisis ekonomi tahun 1997 dan 2008/2009 (Mubarok, 2012 : 1).

Sektor informal di Indonesia sudah sejak lama menjadi tumpuan harapan banyak warga. Mereka memilih (baik dengan sukarela maupun terpaksa) masuk ke sektor informal karena karakteristik sektor ini relatif lebih sederhana. Sektor informal adalah sektor yang tidak terorganisir (unorganized), tidak teratur (unregulated), dan kebanyakan legal namun tidak terdaftar (unregistered) 
(Bappenas, 2009 : 2). Fenomena perkotaan tersebut juga dialami oleh Kota Bogor. Kota dengan jumlah penduduk 1.004.831 jiwa (BPS, 2013), menghadapi problematika penanganan sektor informal yaitu Pedagang Kaki Lima (PKL). Dalam dokumen Rencana Strategis Kota Bogor 2005 - 2009 dan RPJMD 2010 - 2014, penanganan PKL menjadi salah satu dari empat prioritas pembangunan di Kota Bogor. Namun, hingga awal tahun 2014 penanganan PKL belum menampakkan hasil sesuai rencana. Kondisi di lapangan justru menampakkan kesan semakin tidak tertangani, walaupun sudah ditetapkan perangkat kebijakan berupa Peraturan Daerah (Perda) nomor 13 tahun 2005 tentang Penataan Pedagang Kaki Lima.

Beberapa hasil pendataan dan penelitian terdahulu, menunjukkan bahwa jumlah PKL di Kota Bogor semakin besar dari tahun ke tahun (Disperindag; PINBUK; Ruhiyana, 2010 : 2; Mubarok : 2012 : 6-7; Rakhmawati, 2007 : 7). Terjadi peningkatan jumlah PKL dalam kurun waktu 15 tahun terakhir. Pada tahun 1996 jumlah PKL sebanyak 2.140 dan meningkat menjadi 9.710 pada 2012. Hal ini terjadi karena adanya pengaruh krisis ekonomi yang mengakibatkan semakin tingginya angka pengangguran akibat PHK dan sulitnya lapangan kerja formal, sehingga menjadi PKL merupakan pilihan untuk tetap mendapatkan penghasilan (Ruhyana, 2010 : 35 dan Rakhmawati, 2007 : 58).

Langkah-langkah penataan PKL di Kota Bogor terus dilakukan setiap tahun oleh Pemerintah. 3 (tiga) langkah yang dilakukan oleh Pemerintah Kota dalam penataan seperti penertiban PKL, relokasi dan lokalisir lokasi PKL, serta penentuan zona PKL belum tercapai. Belum terlihat tahapan dan fokus pembinaan PKL yang memberikan dampak terhadap penataan PKL dan dapat dijadikan tolak ukur keberhasilan. Tampak beberapa lokasi strategis dan prioritas penanganan seperti 52 di Jalan M.A Salmun, Jalan Nyi Raja Permas, Jalan Dewi Sartika, dan Jalan Merdeka hingga kini masih memerlukan penanganan secara menyeluruh dan terpadu. Untuk itu, diperlukan strategi dalam pembinaan PKL di Kota Bogor, yang menyentuh kebutuhan PKL dan dapat menjadi solusi terhadap permasalahan PKL. Keberhasilan Kota Solo dalam memberikan pembinaan kepada PKL dan menata ruang publik kota, dapat menjadi inspirasi Pemerintah Kota Bogor dalam penataan PKL.

\section{Tujuan Penelitian}

Kajian ini bertujuan untuk mendapatkan alternatif strategi terhadap pembinaan PKL di Kota Bogor yang akan berdampak pada efektivitas penataan PKL. Sedangkan tujuan khusus dari kajian ini, antara lain :

1. Mengidentifikasi dan menganalisis karakteristik PKL di Jalan Dewi Sartika (Sekitar Taman Topi).

2. Mengidentifikasi dan menganalisis faktor-faktor internal dan faktor-faktor eksternal yang berpengaruh terhadap pembinaan PKL di Jalan Dewi Sartika.

3. Merumuskan alternatif strategi dalam penataan PKL di Jalan Dewi Sartika.

4. Menentukan strategi alternatif terbaik, dan Menyusun Program-program yang dapat dilaksanakan oleh Pemerintah Kota Bogor dalam melakukan penataan dan pemberdayaan PKL.

\section{TINJAUAN PUSTAKA}

Pemahaman PKL saat ini telah berkembang dan dilihat dari berbagai sudut pandang. Dalam pandangan pemerintah disebutkan bahwa PKL adalah pelaku usaha yang melakukan usaha perdagangan dengan menggunakan sarana usaha bergerak maupun tidak bergerak, menggunakan prasarana kota, fasilitas sosial, fasilitas umum, lahan dan bangunan milik pemerintah dan/atau swasta yang bersifat sementara/tidak menetap (Permendagri nomor 41 tahun 2012 pasal 1). Pedagang Kaki Lima juga memiliki karakteristik tersendiri. Ramli (1992:58) 
melihat karateristik PKL dari pola dagangannya yaitu :

1) Kebanyakan PKL menjual barang dagangnya dengan harga luncur (sliding price system);

2) terdapat proses tawar menawar yang merefleksikan penetapan harga secara perkiraan saja dan tanpa pembukuan yang ketat;

3) berusaha mendapatkan keuntungan sebanyak-banyaknya dari jual beli yang dilakukan dan bukan untuk mencari langganan tetap;

4) ada mekanisme utang-mengutang kepada grosir atau kreditor.

Penataan dan penertiban PKL di

Kota Bogor berlandasakan kepada peraturan yang telah ditetapkan, antara lain

1) Perda Kota Bogor Nomor 13 Tahun 2005 tentang Penataan PKL.

2) Perda Kota Bogor no. 8 tahun 2006 tentang Ketertiban Umum.

3) Peraturan Walikota Bogor Nomor 25 Tahun 2006 tentang Petunjuk Pelaksanaan Perda Kota Bogor Nomor 13 Tahun 2005 tentang Penataan PKL.

4) Keputusan Walikota Bogor Nomor 511.23.45-146 tahun 2008 tentang Penunjukan Lokasi Pembinaan dan Penataan Usaha PKL sebagaimana telah diubah dengan Keputusan Walikota Bogor Nomor 511.23.45.-63 Tahun 2010 tanggal 4 Pebruari 2010.

\section{METODE PENELITIAN}

Kerangka berfikir pada penelitian ini dapat dilihat pada Gambar 1 dibawah ini.
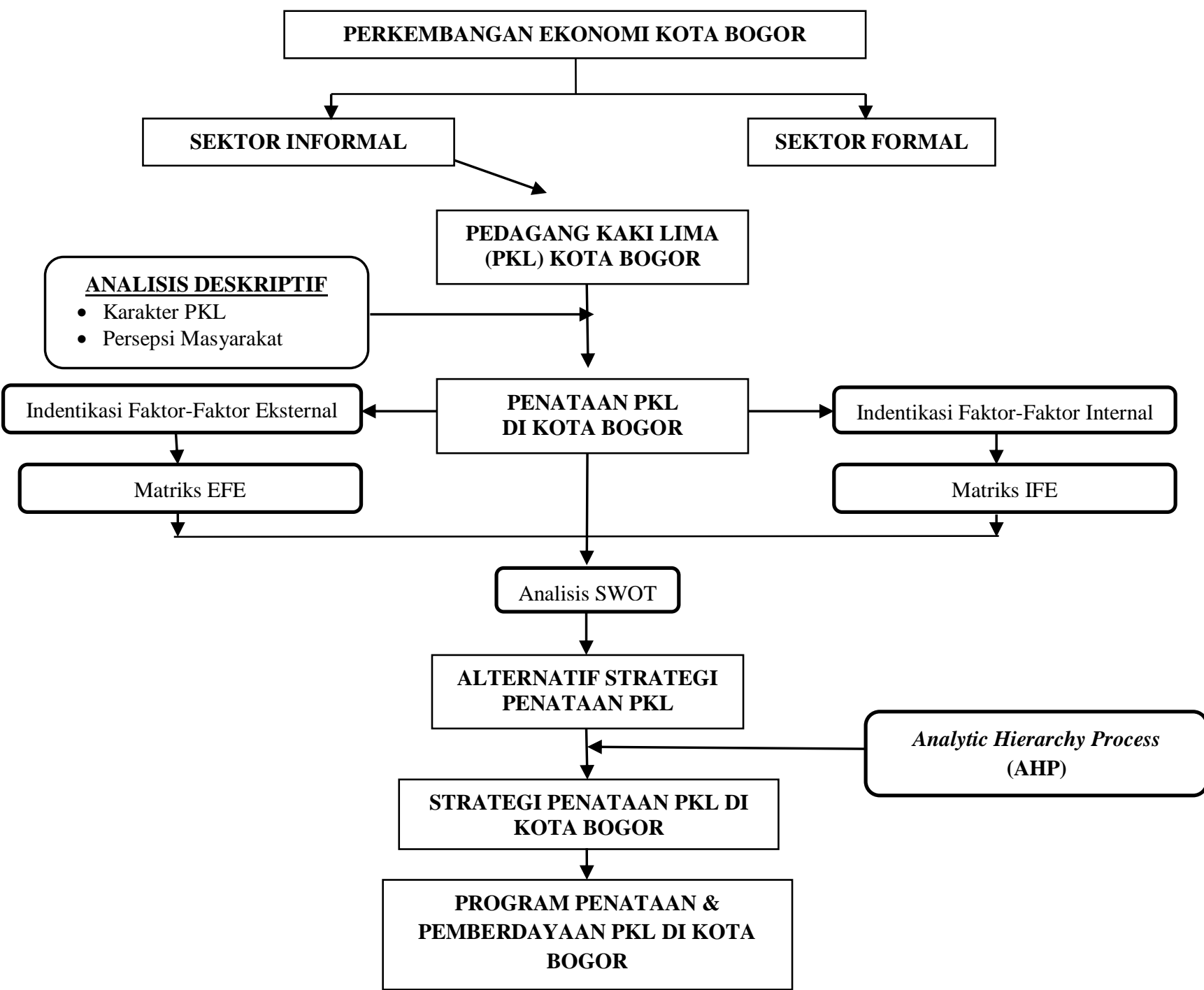

Gambar 1. Kerangka Pemikiran 


\section{Lokasi dan Waktu Penelitian}

Lokasi penelitian dilaksanakan di lokasi prioritas pembinaan PKL di Kota Bogor, sebagaimana ditetapkan dalam Peraturan Daerah Kota Bogor nomor 13 tahun 2005 tentang Penataan PKL, salah satunya yaitu di Jalan Dewi Sartika Bogor. Pemilihan dilakukan secara purposif sesuai dengan maksud dan tujuan kajian ini. Penelitian dilaksanakan mulai bulan Juni sampai September 2014. Kegiatan yang dilakukan meliputi persiapan penelitian, pengumpulan data dan informasi, pengolahan data dan analisis data, serta penulisan dan konsultasi.

\section{Metode Analisis dan Pengambilan Sampel}

Penelitian ini menggunakan metode analisis deskriptif untuk identifikasi karakter PKL dan persepsi masyarakat, metode SWOT untuk identifikasi dan analisis faktor-faktor internal dan eksternal, dan metode Analitycal Hirarki Process (AHP) untuk analisis alternatif strategi. Untuk analisis deskriptif tentang karakteristik PKL di Jalan Dewi Sartika, populasi PKL yang dipilih antara lain pedagang di Jalan Dewi Sartika sebanyak 50 PKL dari jumlah 323 PKL (Kantor Koperasi dan UMKM, 2014). Sementara untuk analisis SWOT dan AHP, sampel ditentukan sebanyak 7 orang yang terdiri dari Asisten Walikota Bidang Pembangunan dan Kemasyarakatan, Anggota DPRD, Kabid Ekonomi Bappeda, Kepala Kantor Koperasi dan UMKM, Kabid Ketertiban Umum Satpol PP, Koordinator PKL Jalan Dewi Sartika, dan Ketua Paguyuban PKL Kota Bogor.

\section{HASIL DAN PEMBAHASAN}

\section{Karakteristik PKL di Jalan Dewi Sartika}

PKL di Jalan Dewi Sartika lebih banyak berjenis kelamin laki-laki $(84 \%)$ dan berumur diatas 25 tahun $(86 \%)$ serta berkedudukan sebagai Kepala rumah tangga (80\%), dengan tingkat pendidikan rata-rata SMA kebawah (54\%). Alasan mereka menjadi PKL karena terkena dampak PHK (34\%) akibat krisis moneter antara tahun 1998. Mayoritas (54\%) telah menjadi PKL diatas 10 tahun.

Jenis dagangan yang paling banyak didagangkan antara lain sepatu sandal (22\%) dan aksesoris elektronik (38\%). Mereka memilih berdagang di Jalan Dewi Sartika dengan alasan ramai pembeli (20\%) dan tidak mampu membeli kios resmi $(20 \%)$. Waktu berjualan dari pukul 7.00 WIB sampai pukul 18.00 WIB (78\%). Lokasi di Jalan Dewi Sartika pada malam hari digunakan oleh PKL yang menjajakan VCD/DVD bajakan.

\section{Persepsi Masyarakat}

Masyarakat banyak yang berbelanja di PKL Jalan Dewi Sartika karena alasan lokasinya mudah dijangkau (49\%) dan harganya murah $(24,5 \%)$. Hal lain yang terungkap dari analisis persepsi masyarakat adalah keberadaan PKL menganggu aktivitas pejalan kaki $(40.8 \%)$ dan menyebabkan lingkungan tidak rapi/semrawut $(24.5 \%)$. Hal ini memiliki kesamaan dengan hasil Litbang Kompas tentang PKL di DKI Jakarta (Kompas, 1 September 2014 hal 27). Masyarakat menginginkan ada penataan terhadap PKL (98\%) dengan melakukan relokasi $(50 \%)$ dan penataan tempat usaha $(29.2 \%)$.

\section{Analisis SWOT}

\section{Identifikasi Faktor Internal-Eksternal}

Untuk mengetahui faktor-faktor strategi yang berpengaruh terhadap penataan PKL di Kota Bogor, khususnya di Jalan Dewi Sartika (seputar Taman Topi) digunakan analisis faktor internal eksternal. Yang menjadi faktor internal adalah Pemerintah Kota Bogor dan Faktor eksternal adalah diluar Pemerintah Kota Bogor. Tahap awal analisis ini adalah mengidentifikasi terlebih dahulu indikator faktor internal yaitu kekuatan dan kelemahan dan indikator faktor eksternal yaitu peluang dan ancaman dalam penataan PKL di Kota Bogor. 


\section{Identifikasi Faktor Internal}

Dalam mengidentifikasi faktor internal, maka dijabarkan dalam aspek kekuatan dan kelemahan dalam menjalankan penataan PKL di Kota Bogor.

A. Kekuatan (Strenght)

1. Penataan PKL Menjadi Prioritas Pembangunan Kota (RPJMD)

2. Terdapat Peraturan Daerah tentang PKL

3. Alokasi Anggaran untuk PKL

4. Terdapat Organisasi Perangkat Daerah (OPD) Menangani PKL

5. Memiliki Lokasi Pasar dan Aset Lahan di Tengah Kota

B. Kelemahan (Weakness)

1. Lemahnya Penegakan Hukum

2. Koordinasi lintas OPD masih belum Maksimal

3. Efektivitas Penggunaan Anggaran

4. Belum Terdapat Validitas Data Dasar PKL dan Perencanaan

5. Kurangnya kerjasama dengan swasta, akademisi, dan Masyarakat

\section{Identifikasi faktor Eksternal}

Dalam mengidentifikasi faktor eksternal, maka dijabarkan dalam aspek peluang dan ancaman dalam menjalankan penataan PKL di Kota Bogor.

A. Peluang

1. Kebijakan Pusat yang mendorong penataan dan pemberdayaan PKL

2. Perkembangan Wisata Kota Bogor

3. Masih terdapat potensi lokasi milik swasta untuk di beli sebagai alternatif relokasi bagi PKL di dalam Kota Bogor

4. Kondisi keamanan yang terjamin

5. Keterlibatan Swasta, Akademisi, dan Masyarakat

B. Ancaman

1. Meningkatnya Pertumbuhan Angka Pengangguran

2. Menurunnya Estetika Tata Ruang Kota (Kekumuhan)

3. Menambah titik Kemacetan Lalu Lintas
4. Munculnya oknum/premanisme dalam Sistem PKL

5. Hilangnya Potensi Pendapatan

Daerah

Untuk melakukan analisis terhadap faktor-faktor strategis yang mempengaruhi penataan PKL di Jalan Dewi Sartika Kota Bogor digunakan matriks Internal Factor Evaluation (IFE) untuk faktor internal dan matriks External Factor Evaluation (EFE) untuk faktor eksternal.

\section{Internal Factor Evaluation (IFE)}

Faktor-faktor strategis yang mempengaruhi penataan PKL di Jalan Dewi Sartika berdasarkan hasil perhitungan bobot dan rating, diketahui bahwa faktor internal yang strategis adalah penataan PKL masuk dalam rencana prioritas pembangunan (RPJMD) dengan nilai sebesar 0.44 dan terdapat Peraturan Daerah tentang penataan PKL dengan nilai 0.44. Faktor ini mempunyai peringkat sebesar 4 yang berarti faktor tersebut merupakan kekuatan utama dibandingkan dengan faktor lain yang dimiliki bagi penataan PKL di Jalan Dewi Sartika.

Selain mengidentifikasi kekuatan internal, matriks IFE juga menunjukkan berbagai kelemahan dalam strategi penataan PKL di Jalan Dewi Sartika. Faktor internal yang memiliki nilai kelemahan terbesar adalah lemahnya penegakan hukum dan koordinasi lintas OPD yang masih belum maksimal, yang memiliki nilai sebesar 0.20. Hal ini menunjukkan bahwa dalam penataan PKL di Kota Bogor harus memperkuat faktor penegakan hukum dan penguataan koordinasi kelembagaan di Pemerintah Kota Bogor yang terkait dalam penataan PKL.

\section{Eksternal Factor Evaluation (EFE)}

Berdasarkan hasil identifikasi
faktor strategis eksternal yang
mempengaruhi penataan PKL di Jalan
Dewi Sartika yang terdiri dari peluang dan
ancaman, kemudian dilanjutkan dengan
evaluasi faktor eksternal menggunakan
matriks EFE (Eksternal Factor


Evaluation). Bobot yang diperoleh menentukan tingkat kepentingan relatif satu faktor eksternal terhadap faktor eksternal lainnya yang berpengaruh pada penataan PKL di Jalan Dewi Sartika.

Berdasarkan analisis EFE diketahui bahwa faktor-faktor kunci eksternal yang memberikan peluang terbesar dalam penataan PKL di Jalan Dewi sartika adalah adanya keterlibatan swasta, akademisi, dan masyarakat dalam proses penataan PKL. Peluang ini mendorong seluruh pemangku kepentingan di Kota Bogor terlibat dalam agenda kota yaitu penataan PKL. Nilai skor terbesar yang dimiliki faktor kunci eksternal ini yaitu sebesar 0,33 dengan bobot 0,11 dan rating sebesar 3. Faktor eksternal yang memberikan ancaman terbesar bagi penataan PKL di Jalan Dewi sartika adalah menurunnya estetika tata ruang kota, menambah titik kemacetan, dan hilangnya potensi PAD yang ditunjukkan dengan bobot 0,10 dan rating 3 sehingga skornya menjadi 0.30 . Hal ini menunjukkan bahwa dalam penataan PKL harus memperhatikan aspek esetetika kota, jumlah pengangguran, dan PAD Kota Bogor.

\section{Matrik SWOT}

Kemudian berdasarkan hasil identifikasi, perhitungan dan analisis terhadap faktor-faktor yang menjadi kekuatan, kelemahan, peluang dan ancaman melalui analisis internal dan eksternal dengan matriks IFE dan EFE tersebut di atas, maka dapat disusun atau dibuat analisis dengan menggunakan metode SWOT.

\section{Tabel 1 Matrik SWOT}

\begin{tabular}{|c|c|c|}
\hline & Kekuatan $(\mathbf{S})$ & Kelemahan (W) \\
\hline Faktor Eksernal & $\begin{array}{l}\text { 1. Penataan PKL menjadi } \\
\text { Prioritas Pembangunan } \\
\text { Kota (RPJMD) } \\
\text { 2. Terdapat Peraturan Daerah } \\
\text { tentang PKL } \\
\text { 3. Alokasi Anggaran Untuk } \\
\text { Penataan PKL } \\
\text { 4. Terdapat Organisasi } \\
\text { Perangkat Daerah (OPD) } \\
\text { Menangani PKL } \\
\text { 5. Memiliki Lokasi Pasar dan } \\
\text { Aset Lahan di tengah Kota }\end{array}$ & $\begin{array}{l}\text { 1. Lemahnya Penegakan } \\
\text { Hukum } \\
\text { 2. Koordinatasi lintas OPD } \\
\text { masih belum maksimal } \\
\text { 3. Efektivitas Penggunaan } \\
\text { Anggaran } \\
\text { 4. Data Dasar PKL dan } \\
\text { Perencanaan Penataan PKL } \\
\text { 5. Kurangnya kerjasama dengan } \\
\text { swasta, akademisi dan } \\
\text { masyarakat }\end{array}$ \\
\hline $\begin{array}{l}\text { Peluang }(\mathbf{O}) \\
\text { 1. Kebijakan Pusat yang mendorong } \\
\text { penataan dan pemberdayaan PKL } \\
\text { 2. Perkembangan Wisata Kota Bogor } \\
\text { 3. Masih terdapat potensi lokasi milik } \\
\text { swasta untuk di beli sebagai alternatif } \\
\text { relokasi bagi PKL di dalam Kota } \\
\text { Bogor } \\
\text { 4. Kondisi keamanan yang terjamin } \\
\text { 5. Keterlibatan Swasta, Akademisi, dan } \\
\text { Masyarakat }\end{array}$ & $\begin{array}{l}\text { Review Kebijakan Tentang } \\
\text { PKL di Kota Bogor (S1, S2, } \\
\text { S4, S4, O1, O5) }\end{array}$ & $\begin{array}{l}\text { Meningkatkan Kemitraan } \\
\text { Pemerintah dengan PKL ( W1, } \\
\text { W2, W4, O1, O2) }\end{array}$ \\
\hline $\begin{array}{l}\text { Ancaman (T) } \\
\text { 1. Meningkatnya Pertumbuhan Angka } \\
\text { Pengangguran } \\
\text { 2. Menurunnya Estetika Tata Ruang Kota } \\
\text { 3. Menambah titik Kemacetan Lalu } \\
\text { Lintas } \\
\text { 4. Munculnya oknum/premanisme dalam } \\
\text { Sistem PKL } \\
\text { 5. Hilangnya Potensi Pendapatan Daerah }\end{array}$ & $\begin{array}{l}\text { Memfasilitasi Ruang Usaha } \\
\text { dan Rasa Aman Berusaha (S1, } \\
\text { S3, S5, T1, T2, T4) }\end{array}$ & $\begin{array}{l}\text { Mengoptimalkan Sarana } \\
\text { Prasarana Kota (W2, W3, W4, } \\
\text { T2,T3) }\end{array}$ \\
\hline
\end{tabular}


Berdasarkan hasil analisis SWOT, diperoleh 4 (empat) alternatif strategi yang dapat digunakan dalam penataan PKL di Jalan Dewi Sartika Kota Bogor.

1. Strategi S-O merupakan strategi yang menggunakan kekuatan untuk memanfaatkan peluang dalam penataan PKL. Alternatif strategi yang dihasilkan yaitu perlu dilakukan Review Kebijakan PKL di Kota Bogor.

2. Strategi S-T adalah strategi yang menggunakan kekuatan untuk menghindari ancaman yang ada dalam penataan PKL di Jalan Dewi Sartika. Kombinasi kekuatan dan ancaman itu menghasilkan alternatif strategi memfasilitasi Ruang Usaha dan Rasa Aman Berusaha.
3. Strategi W-O adalah strategi yang mengatasi kelemahan dengan memanfaatkan peluang yang ada dalam penataan PKL di Jalan Dewi Sartika Kota Bogor. Strategi tersebut menghasilkan alternatif strategi meningkatkan kemitraan pemerintah dengan PKL.

4. Strategi W-T adalah strategi yang didasarkan pada kegiatan yang bersifat bertahan dan ditujukan untuk meminimalisasi kelemahan yang ada serta menghindari ancaman dalam penataan PKL di Jalan Dewi Sartika Kota Bogor. Berdasarkan analisis strategi alternatif yang dapat di lakukan adalah mengoptimalkan sarana prasana kota sesuai peruntukkannya.

\section{ANALITYC HIERARCHY PROCESS (AHP)}

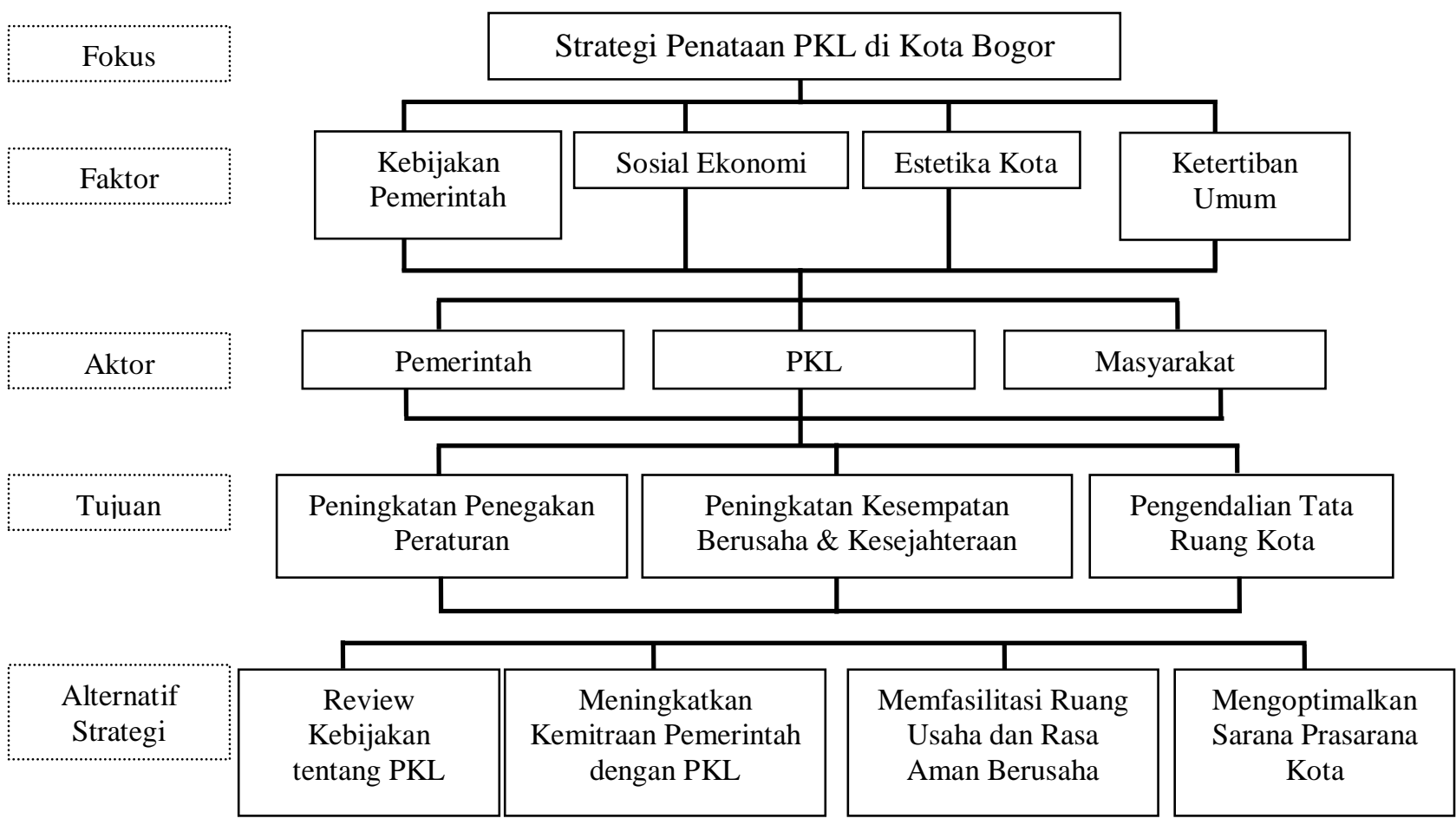

Gambar 2. Struktur Hirarki Strategi Penataan PKL di Kota Bogor 
Berdasarkan hasil proses analisis menggunakan expert choice terhadap alternatif strategi penataan PKL, maka didapatkan hasil akhir urutan prioritas sebagai berikut :

1. Review Kebijakan tentang PKL (0.350)

2. Meningkatkan Kemitraan Pemerintah dengan PKL (0.267)

3. Memfasilitasi Ruang Usaha dan Rasa

Aman Berusaha (0.218)
4. Mengoptimalkan Sarana Prasarana Kota (0.165)

Hasil analisis AHP menggunakan Expert Choice dapat disajikan pada Gambar 3 dan 4. Gambar 4 menjelaskan hasil analisis sensitivitas terhadap pilihan alternatif kebijakan.

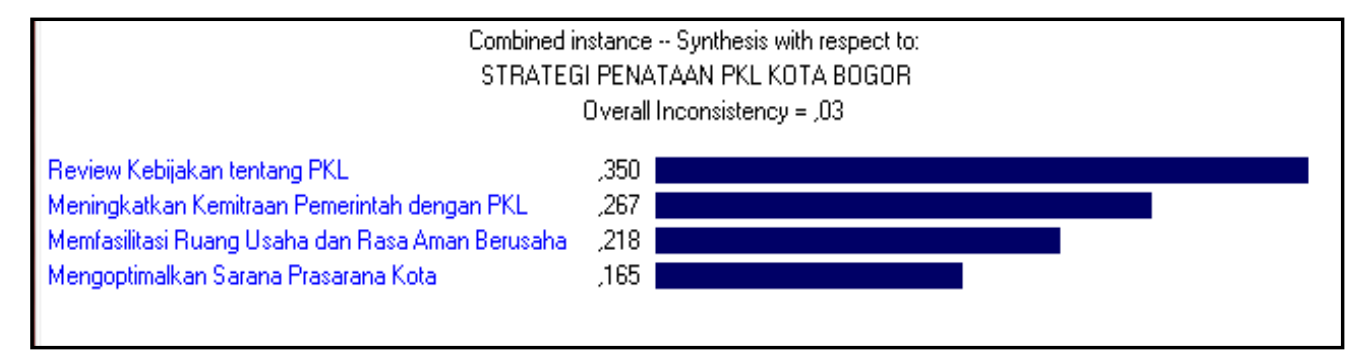

Gambar 3. Hasil Analisis Menggunakan Expert Choice
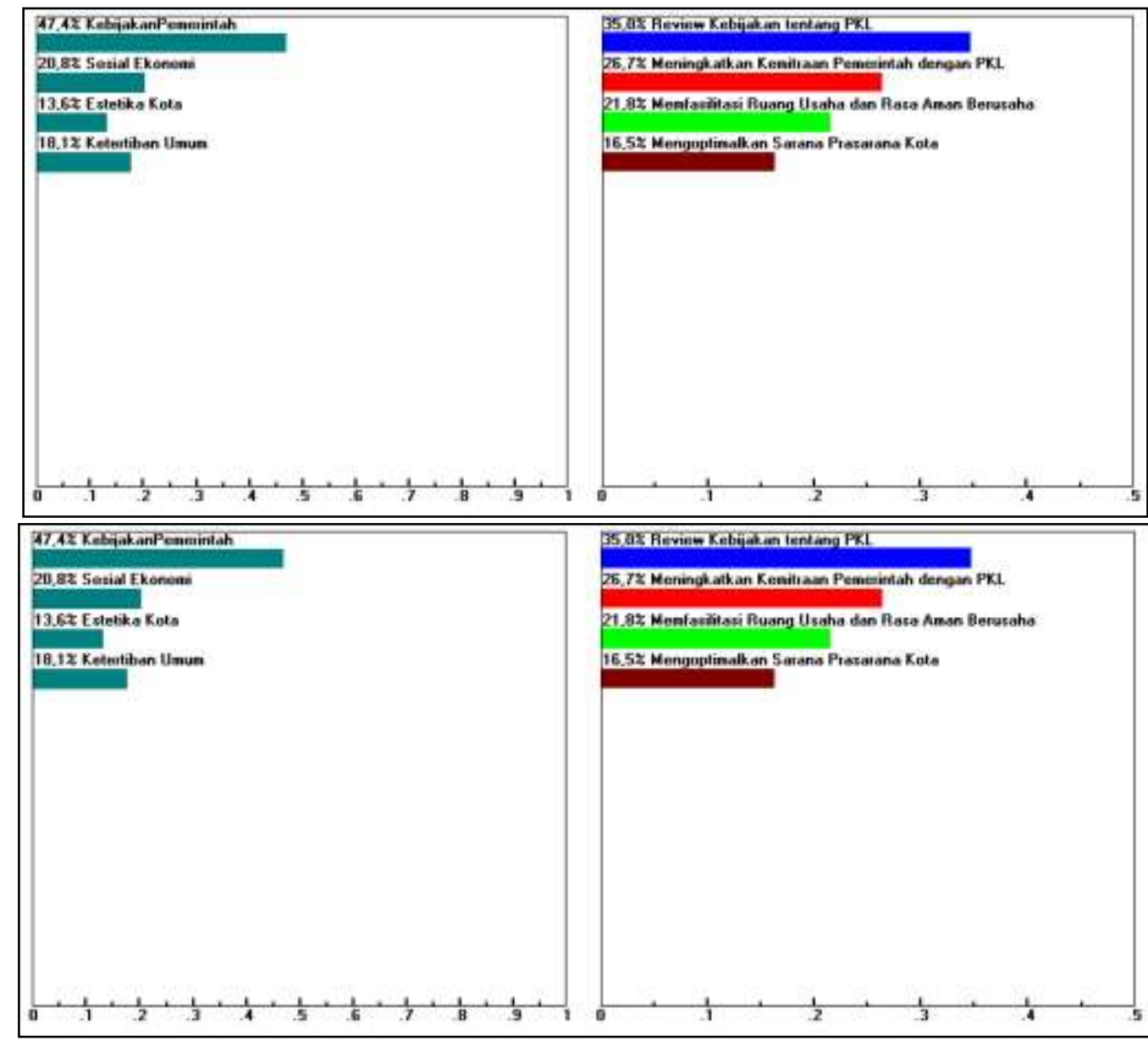

Gambar 4. Dinamik untuk analisis Sensitivitas 


\section{RANCANGAN PROGRAM PENATAAN PKL}

Berdasarkan hasil analisis terhadap alternatif kebijakan, maka disusun rancangan program beserta indikasi waktu pelaksanaan dan instansi yang bertanggung jawab, sebagaimana dapat dilihat pada Tabel 2.

\section{Tabel 2 Rancangan Program Penataan PKL di Kota Bogor}

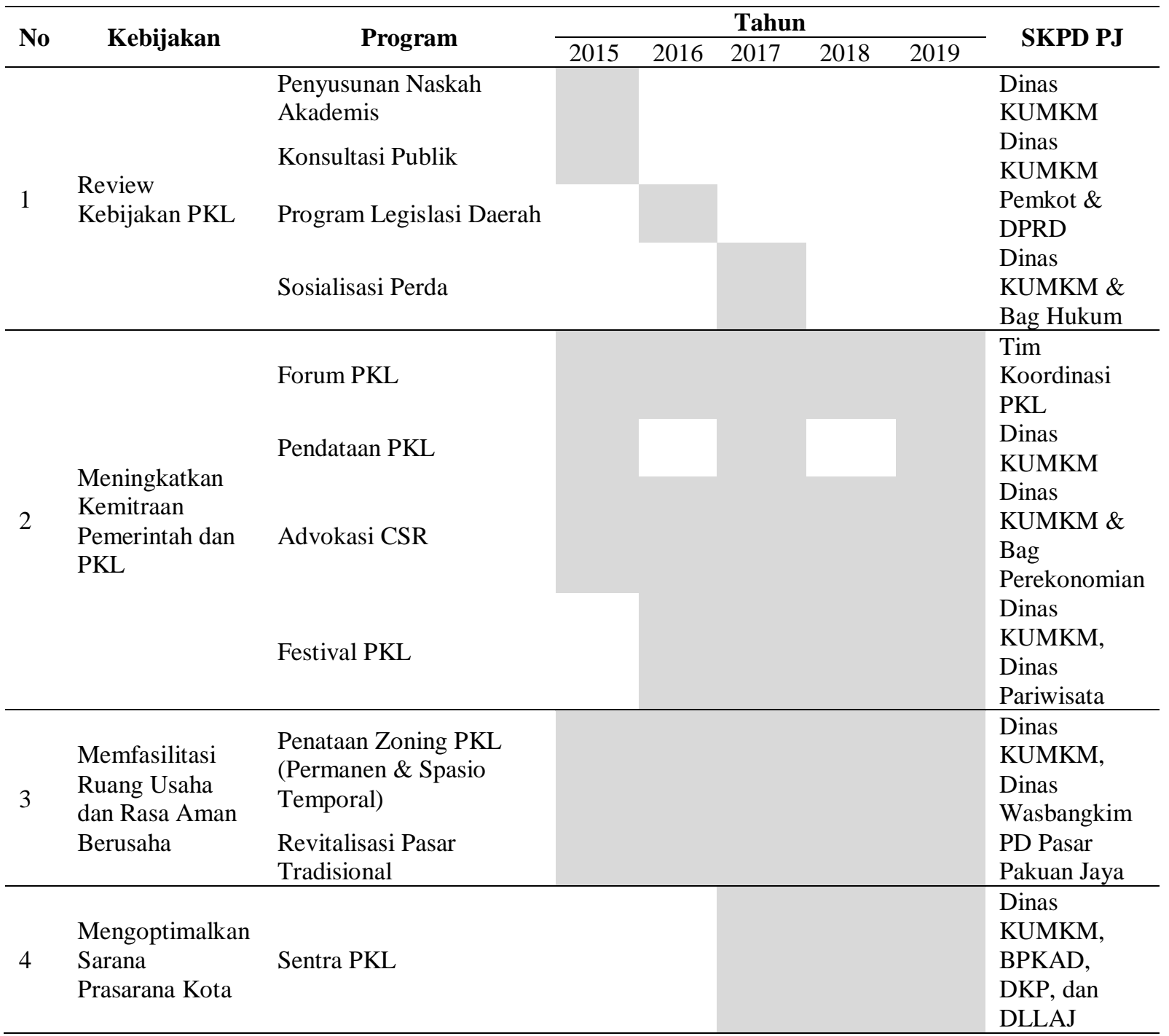

\section{SIMPULAN DAN SARAN}

\section{Simpulan}

Beberapa simpulan dari hasil analisis penelitian antara lain :

1. Karakteristik PKL di Jalan Dewi Sartika Kota Bogor didominasi oleh laki-laki yang merupakan Kepala Rumah Tangga, dengan rata-rata telah berjualan di lokasi tersebut diatas 10 tahun. Tingkat pendidikan relatif rendah dan menjadi PKL akibat terkena dampak PHK saat krisis moneter. Memiliki waktu usaha rata-rata selama 10 jam, antara jam 7 sampai jam 18.00 WIB. Berjualan di Jalan Dewi sartika karena banyak pembeli yang melalui jalan tersebut dan tidak mampu membeli kios resmi.

2. Masyarakat masih membutuhkan PKL, namun diperlukan penataan agar tidak mengganggu akses pejalan kaki dan tidak menimbulkan kesemrawutan kota. 
Penyediaan lokasi yang tertata bagi PKL merupakan harapan masyarakat agar Kota Bogor menjadi nyaman.

3. Dari hasil analisis SWOT diperoleh alternatif kebijakan yang kemudian dianalisis tingkat kepentingannya dengan metode AHP, antara lain :

a. Review Kebijakan tentang PKL

b. Meningkatkan Kemitraan Pemerintah dengan PKL

c. Mengoptimalkan Sarana Prasarana Kota

d. Memfasilitasi Ruang Usaha dan Rasa Aman Berusaha

\section{Saran}

1. Pemerintah Kota Bogor harus melakukan review terhadap kebijakan penataan PKL, yaitu dengan mereview Perda 13 tahun 2005 tentang PKL. Hal ini dikarenakan substansi Perda sudah tidak sesuai dengan kondisi di lapangan. 3 (tiga) kawasan prioritas, salah satunya Jalan Dewi Sartika yang harus ditata dengan target tahun 2007, hingga saat ini masih belum tertangani. Selain itu terdapat kebijakan Pemerintah pusat yang mendorong proses penataan dan pemberdayaan PKL melalui Perpres 125 tahun 2014 dan Permendagri nomor 41 tahun 2012.

2. Penguatan kelembagaan organisasi perangkat daerah yang menangani urusan PKL dari Kantor Koperasi dan UMKM menjadi Dinas Koperasi dan UMKM pada perubahan OPD 2015, perlu diiringi dengan konsep perencanaan yang terintegrasi antar beberapa aspek yang terkait dengan penataan dan pemberdayaan PKL. Hal ini agar program penataan PKL yang masuk dalam program prioritas pembangunan (RPJMD) 2014-2019 dapat berjalan secara efektif.

3. Perlu pembentukan forum PKL, agar aspirasi dan ide PKL dapat didengar dan menjadi bagian dari pengambil keputusan dalam penataan PKL.

4. Pemerintah perlu melibatkan PKL, masyarakat, dan akademisi dalam mempersiapkan konsep penataan kawasan Plaza Kapten Muslihat (Taman Topi dan Taman Ade Irma Suryani) yang akan diserahterimakan dari pihak swasta kepada Pemerintah Kota Bogor pada tahun 2018 dengan konsep integrasi penyediaan ruang publik dan ruang usaha untuk PKL di sekitar Jalan Dewi Sartika.

\section{DAFTAR PUSTAKA}

Bappeda Kota Bogor, 2014. Rancangan Rencana Pembangunan Jangka Menengah Daerah (RPJMD) Kota Bogor 2015-2019.

Bappenas, 2009. Kajian Evaluasi Pembangunan Sektoral : Peran Sektor Informal Sebagai Katup Pengaman Masalah Ketenagakerjaan. Deputi Evaluasi Kinerja Pembangunan. Jakarta.

BPS Kota Bogor, 2014. Bogor Dalam Angka 2013. Kerjasama Bappeda Kota Bogor dengan BPS Kota Bogor.

Dimas, Harlan, 2008. Street Vendors : "Urban Problem and Economic Potential". Fakultas Ekonomi Universitas Padjajaran. Bandung.

Firdaus M, Harmini, Farid, 2011. Aplikasi Metode Kuantitatif Untuk Manajemen dan Bisnis. PT. Penerbit IPB Press. Kota Bogor.

Gibson, Bill dan Bruce Kelley, March 1994. A clasical theory of The Informal Sector. Journal The Manchaster School Vol LXII no 1, Hal 81 - 96. Cambridge. USA.

Iswanto, Danoe, 2007. Tinjauan Keberadaan Pedagang Kaki Lima (PKL), Aspek Pedestrian Area Dan Parkir Di Kawasan Solo Grand Mall (SGM). Jurnal Ilmiah Perancangan Kota dan Permukiman ENCLOSURE Volume 6 No. 2. Juni 2007.

Loayza, Norman, 1997. Policy Research Working Paper 1727 : The Economics of The Informal Sector. Macroeconomics and Growth 
Division, World Bank. Washington DC.

Mubarok, Ahmad, 2012. Karakteristik Dan Permasalahan Pedagang Kaki Lima (PKL) Serta Strategi Penataan Dan Pemberdayaannya Dalam Kaitan Dengan Pembangunan Ekonomi Wilayah Kota Bogor. Disertasi IPB. Bogor.

Peraturan Daerah Kota Bogor Nomor nomor 13 tahun 2005 tentang Penataan Pedagang Kaki Lima.

Peraturan Menteri Dalam Negeri Nomor 41 Tahun 2012 tentang Pedoman Penataan dan Pemberdayaan Pedagang Kaki Lima.

Ramli MS, Rusli, Sektor Informal Perkotaan Pedagang Kaki Lima, Jakarta, Ind-Hil.co, 1992.

Rakhmawati, 2007. Penataan Pedagang Kaki Lima (Studi Kasus Pengawasan dan Pengendalian Pedagang Kaki Lima Pasca Penataan di J1. M.A Salmun - Jl. Dewi Sartika dan Jl. Nyi Raja Permas Kota Bogor). Pasca Sarjana Departemen Ilmu Kesejahteraan Sosial, Konsentrasi Pembangunan Sosial, FISIP Unversitas Indonesia. Depok.
Ruhiyana, Dadang, 2010. Strategi Penataan Pedagang Kaki Lima di Kota Bogor. Sekolah Pasca Sarjana Institut Pertanian Bogor. Tesis. Bogor.

Rustiandi, Ernan dkk, 2011. Perencanaan dan Pengembangan Wilayah. Edisi kedua. Yayasan Pustaka Obor dan Crestpent Press IPB. Jakarta.

Setia M, Resmi. 2008. Ekonomi Informal Perkotaan : Sebuah Kasus Tentang Pedagang Kaki Lima di Kota Bandung. Akatiga. Bandung.

Yeti, Sarjono, 2005. Pergulatan Pedagang Kaki Lima di Perkotaan (pendekatan kualitatif), MUP-UNS. Solo.

Winarso, Haryo, 2008. Sektor Informal yang Teroganisasi : Menata Kota untuk Sektor Informal. Buletin Tata Ruang Edisi November-Desember 2008 Kategori Wacana. Kementerian PU. Jakarta.

Wahyuni, Daru, Agustus 2005. Jurnal Economia, Kajian ilmiah ekonomi dan bisnis, volume 1 nomor 1 . Program Studi Pendidikan Ekonomi Koperasi, Universitas Negeri Yogyakarta. Yogyakarta. 